\title{
Speech Perception in Infancy Predicts Language Development in the Second Year of Life: A Longitudinal Study
}

\author{
Feng-Ming Tsao, Huei-Mei Liu, and Patricia K. Kuhl
}

\begin{abstract}
Infants' early phonetic perception is hypothesized to play an important role in language development. Previous studies have not assessed this potential link in the first 2 years of life. In this study, speech discrimination was measured in 6-month-old infants using a conditioned head-turn task. At 13, 16, and 24 months of age, language development was assessed in these same children using the MacArthur Communicative Development Inventory. Results demonstrated significant correlations between speech perception at 6 months of age and later language (word understanding, word production, phrase understanding). The finding that speech perception performance at 6 months predicts language at 2 years supports the idea that phonetic perception may play an important role in language acquisition.
\end{abstract}

Language development is one of the major achievements of infancy and early childhood. The milestones of linguistic achievement have been documented across cultures and suggest that infants follow a set of universal stages both in speech production and speech perception. Wide consensus now exists among investigators, for example, on the stages in speech production exhibited by young infants in American English and other languages; a universal progression from cooing (1 to 4 months), to babbling (5 to 10 months), to meaningful speech (10 to 18 months) is shown (Ferguson, Menn, \& Stoel-Gammon, 1992).

Research has also documented stages in speech perception development that have been shown in experimental tests on infants across cultures. Infants begin life with a universal capacity to differentiate the fine-grained acoustic events that differentiate

Feng-Ming Tsao, Institute for Learning and Brain Sciences, University of Washington, and Department of Psychology, National Taiwan University, Taiwan; Huei-Mei Liu, Department of Special Education, National Taiwan Normal University, Taiwan; Patricia K. Kuhl, Institute for Learning and Brain Sciences, University of Washington.

We thank Erica Stevens for assistance with all aspects of the study, Virpi Lahteenmaki for help with participant testing, and Barbara Conboy for helpful comments on the manuscript. During the revision of this manuscript, the first author was supported by the National Taipei Teachers College, Taiwan. Funding for the research was provided by a grant to the third author from the National Institutes of Health (HD37954); the William P. and Ruth Gerberding University Professorship; the University of Washington Institute for Learning and Brain Sciences; and the Talaris Research Institute and Apex Foundation, the family foundation of Bruce and Jolene McCaw.

Correspondence concerning this article should be addressed to Feng-Ming Tsao, Department of Psychology, National Taiwan University, Taipei, Taiwan 106. Electronic mail may be sent to tsaosph@mail2000.com.tw. phonemes across languages, and this ability is exhibited until about 6 months of age. For example, in the early months of life, young infants have been shown to discriminate a 20-ms difference in voice onset time (VOT), an acoustic difference that is sufficient to distinguish English voiced (/b, d, g/) from voiceless $(/ p, t, k /)$ stop consonants (e.g., Eimas, Siqueland, Jusczyk, \& Vigorito, 1971). Infants' sensitivity to this subtle acoustic difference also allows them to discriminate Kikuyu (or Spanish) prevoiced phonetic units from voiceless unaspirated phonetic units, an ability that has been demonstrated in young infants both behaviorally (Streeter, 1976) and using event-related potential brain measures (RiveraGaxiola, Silva-Pereyra, \& Kuhl, in press). Subtle acoustic differences among vowel sounds are also discriminated, allowing infants to distinguish the vowels of many languages early in life (e.g., Aldridge, Stillman, \& Bower, 2001; Trehub, 1973).

The fine-grained perceptual skills shown early in infancy raise a question for developmental psychologists studying language: How do infants use the exquisite speech perception skills shown in early infancy in language acquisition? What role does early speech perception play in later language learning? There is a lack of developmental language research attempting to bring the fields of early speech perception and later language acquisition together. The literature attests to infants' early speech perception abilities but fails to explain whether or how infants' abilities to perceive phonetic differences play a role in language development. Although several researchers have raised this issue, asserting that infants' early phonetic abilities must be

(C) 2004 by the Society for Research in Child Development, Inc. All rights reserved. 0009-3920/2004/7504-0007 
important for later language acquisition (Jusczyk, 1997; Kuhl, 2000; Werker \& Tees, 1999), few studies have directly assessed the potential link between the two.

The purpose of the present study was to test a specific hypothesis about the connection between infants' early speech perception abilities and their later abilities to acquire language. We posited a strong, positive association between an infant's speech perception performance at 6 months of age and that infant's scores on measures of language acquisition at 2 years. We tested the hypothesis using a well-researched and often-used measure of speech perception ability (conditioned head turn [HT]; see Polka, Jusczyk, \& Rvachew, 1995) to test infants at 6 months of age and used subsequent follow-up tests to assess language skill in those same infants at three ages: 13, 16, and 24 months of age. No previous studies have examined the potential connection between speech perception and language acquisition in children under age 3 .

The hypothesized association between infants' early phonetic abilities and their later language skills is supported by three linked arguments: (a) recent studies show that speech discrimination performance in infancy does not reach adult levels and that individual variability is large - we argue that differential ability in initial phonetic perception could affect language acquisition; (b) infants' phonetic perception skills are vital to the identification of words in running speech, and children with better phonetic skills may advance more quickly toward word acquisition; and (c) existing studies of children with language impairments often show deficits in children's phonetic perception skills, suggesting a relation between poor phonetic skills and language problems.

Consider first the performance levels of infants on tests of early speech perception and the variability shown in the infant population. Historically, research on infant speech perception examined group performance. Eimas and colleagues (Eimas, 1974, 1975; Eimas et al., 1971), for example, and most other early investigators, used high-amplitude sucking (HAS) as a measure of infant speech discrimination ability. HAS compares performance between an experimental and a control group. Discrimination is evidenced by group differences rather than by performance of individual infants (Kuhl, 1985; Polka et al., 1995). Studies by Werker and colleagues (Werker \& Tees, 1984) and Kuhl and colleagues (Kuhl, 1979, 1983) employed the conditioned HT technique, which assesses performance on both change and control trials in individual infants. The use of the HT technique permits the calculation of a percent correct measure and the calculation of an unbiased estimate of sensitivity, $d^{\prime}$. However, these experimenters only reported data on the proportion of infants who met a preestablished criterion threshold (e.g., Werker \& Tees, 1984) or the average number of trials required to meet such a criterion (Kuhl, 1979, 1983) rather than individual infants' levels of performance.

Recent tests examined infants' absolute levels of performance on tests of speech discrimination (e.g., Kuhl, Stevens, et al., 2004; Kuhl, Tsao, \& Liu, 2003; Liu, Kuhl, \& Tsao, 2003; Polka \& Bohn, 1996; Tsao, 2001). These data reveal two things relevant to the present investigation: First, on average, infant performance does not approach adult levels, and second, there is considerable variability in performance across infants. In Kuhl, Stevens, et al. (2003), American and Japanese infants were tested on the /ra-la/ phonetic contrast at 6 to 8 and 10 to 12 months. The resulting tests showed that although infant performance on consonant discrimination at 6 to 8 months is solidly above chance, it is substantially below adult levels. American 6- to 8-month-olds perform on average at $63.7 \%$ correct, with a range extending from $43 \%$ to $93 \%$ correct. Japanese 6- to 8month-olds show the equivalent pattern, with a mean score of $64.7 \%$ correct and a range of $47 \%$ to $87 \%$. By 10 to 12 months of age, American infants improve as a group, performing at $73.8 \%$ correct, though variability remains large; individual performance ranges from $43 \%$ to $100 \%$. American adults perform at $99.2 \%$ correct on this native language / r-1/ contrast (Zhang, 2002). These data suggest that: (a) phonetic perception is not uniform in the population of infants at 6 to 8 months, (b) average performance increases for native language consonants between 6 to 8 and 10 to 12 months but remains variable at 10 to 12 months, and (c) performance at neither age, on average, approaches adult levels. The question addressed here is whether the variance observed in infants' early phonetic perception performance is related to the variance in later language development.

The variability seen in infants' perception of speech raises a more fundamental issue: How might early phonetic perception skill contribute to language development? There is increasing evidence that in the first year of life infants are acquiring detailed information about language by listening and analyzing linguistic input (Jusczyk, 1997; Kuhl, 2000; Werker \& Tees, 1999). Studies show, for example, that infants' exposure to ambient language results in rapid learning. By 6 months of age, infants engage in a detailed analysis of the distributional properties of 
sounds contained in the language they hear, and this alters perception to produce more native-like phonetic processing (Kuhl, Williams, Lacerda, Stevens, \& Lindblom, 1992; Maye, Werker, \& Gerken, 2002). By 10 to 12 months of age, consonant discrimination shows a steep decline for non-native phonetic units, again reflecting a change that depends on linguistic experience (Werker \& Tees, 1984). The ability to discern phonetic differences in language input is essential for the kinds of distributional analyses that infants appear to be performing. Infants whose phonetic skills are advanced may progress sooner toward native language processing. Native language processing would in turn advance infants' abilities by allowing them to process language using the phonetic cues that are pertinent to their native language.

Resolving phonetic differences is essential to the detection of phonotactic patterns, patterns that describe combinations of phonemes that are legal in the child's native language and patterns that characterize words in the child's native language. Because spoken words are embedded in a continuous acoustic stream, with no clear acoustic boundaries between them, infants rely on statistical relations between phones and syllables, including distributional information (Friederici \& Wessels, 1993; Mattys, Jusczyk, Luce, \& Morgan, 1999) and transitional probabilities (Goodsitt, Morgan \& Kuhl, 1993; Saffran, Aslin, \& Newport, 1996) to segment words from the speech stream. Between 6 and 9 months of age, infants have been shown to use phonotactic patterns to segment words from running speech (Friederici \& Wessels, 1993; Mattys et al., 1999). This requires prior analysis of the phonetic cues contained in speech. Individual differences in the ability to detect phonetic cues could therefore potentially modulate the detection of likely word candidates.

Experimental studies that directly assess how infants' phonetic abilities are put to work in word learning have been conducted by Werker and her colleagues (Stager \& Werker, 1997; Werker, Fennell, Corcoran, \& Stager, 2002). In these experiments, infants attempt to learn new words using phonetically similar syllable pairs that are easily confused. Infants' discrimination of the phonetic contrasts is necessary to establish the association between speech sounds and novel objects in such wordlearning experiments, and Werker's experiments illustrate that word-learning tasks challenge infants' speech perception skills. These experiments indicate that the task of associating sounds and objects is sufficiently difficult that infants at 14 months cannot do so unless the phonetic units being used in the word association task are very different from one another. When presented with novel objects and novel words, 14-month-old infants fail to associate phonetically similar names (e.g., bih-dih) with unfamiliar objects. At 17 months, infants show improvement, but they do not fully succeed at the task until 24 months. Children thus depend on their abilities to perceive phonetic distinctions to associate a sound pattern with a lexical item. An individual infant with advanced speech perception skills might therefore be expected to show advanced wordlearning skills.

A third source of evidence is indirect, but relevant: The phonetic abilities of children diagnosed with reading disorders, learning disabilities, or language impairment in the form of specific language impairment (SLI) have often been shown to be deficient. In a variety of studies, children with learning disabilities or reading disabilities perform significantly lower on speech perception tasks. Compared with an age-matched control group, children with reading disabilities were poorer than age-matched controls on the discrimination of consonants in word pairs that differed by only one phoneme (Reed, 1989). Several studies also reported performance differences between children with dyslexia and controls in tests of categorical perception with consonant sounds (Godfrey, Syrdal-Lasky, Millay, \& Knox, 1981; Manis et al., 1997; Reed, 1989; Werker \& Tees, 1987). Similar findings, using both brain and behavioral measures, have been reported for children with various forms of learning disabilities (Bradlow et al., 1999; Kraus et al., 1996). Not all studies report that speech perception deficits in children with dyslexia reach significance (Adlard \& Hazan, 1998; Hurford \& Sanders, 1990; Manis et al., 1997), but the direction of the effect is consistent across studies.

Further evidence of a link between deficiencies in speech perception and language acquisition has been shown in school-age children with SLI (Leonard, McGregor, \& Allen, 1992; Stark \& Heinz, 1996a, 1996b; Sussman, 1993, 2001; Tallal \& Piercy, 1974, 1975). Studies have repeatedly shown that SLI children perform more poorly than age-matched controls. Tests on consonant perception indicate that SLI children perform significantly more poorly than controls in the perception of acoustic cues such as formant transition, VOT, and frication noise (Leonard et al., 1992; Tallal \& Piercy, 1975; Tallal \& Stark, 1981). Compared with age-matched controls, tests on vowel perception show deficits for SLI children when vowels are presented as steady-state formants or with formant transitions (Sussman, 2001), when they are of short duration (Stark \& Heinz, 1996b), 
and when they are in a multisyllabic context (Leonard et al., 1992). To summarize, in studies in which children with a variety of impairments that involve language are compared with age-matched controls, measures of speech perception typically show that children with language-related difficulties also have significant deficits in speech perception.

The foregoing arguments that skill in phonetic analysis is essential for the acquisition of higher order language units does not, however, provide the needed data. Is there any evidence to suggest a relationship between early speech perception abilities and later language skills? One source of evidence derives from retrospective studies of newborns' brain-wave patterns in response to speech as predictors of later language delay in children between 3 and 8 years of age. Molfese and colleagues (Molfese, 2000; Molfese \& Molfese, 1985, 1997) showed that when 3-, 5-, and 8-year-old children were classified into normal- and low-language performance groups, based on standardized tests, a discriminant function analysis of their brain waves as newborns predicted their classification with about $80 \%$ accuracy.

Although previous studies provide some support for the hypothesized connection between early speech perception and later language development, there are no prospective longitudinal studies examining the relation between a specific measure of early speech perception and a specific set of language skills in young children; in fact, no studies have been conducted in children under 3 . The purpose of the present study was to test this hypothesis. The specific aim of the study was to determine whether individual differences in a standard behavioral measure of phonetic discrimination in 6-month-old English-learning infants would predict individual differences in language performance at three later time points: 13, 16, and 24 months of age.

The speech perception task used in the current study is a highly sensitive behavioral measure of infant speech perception: HT conditioning, a technique used in many studies of infant speech perception (Kuhl, 1985; Polka et al., 1995; Werker, Polka, \& Pegg, 1997) and one that allows absolute performance measures to be assessed in individual infants. Previous studies indicate that the HT task provides a sensitive measure of an individual infant's speech perception performance (Lalonde \& Werker, 1995; Liu et al., 2003). The MacArthur Communicative Development Inventories (CDIs), a well-established measure of language development, were used to measure language outcomes at 13, 16, and 24 months of age (Fenson et al., 2000; Fenson et al., 1994).
Our design relies on the correlational approach. A significant correlation between early phonetic perception performance and later language development forges an associative link but does not establish a causal relationship. Of importance to the interpretation of an association is the examination of other variables that could mediate the observed link. One feature of the study was the inclusion of measurements of parental variables, such as age, education, and work status, to examine the relationship between these factors and infants' early speech perception and later language skills.

The effect of parental socioeconomic status (SES) on infant speech perception has not been studied, and support for the idea that parental SES relates to language development is mixed. For example, maternal SES has been shown to contribute to lexical comprehension and production in 20-month-olds, independent of maternal verbal ability (Bornstein, Haynes, \& Painter, 1998). In other studies, SESassociated differences in child language development have been attributed to the amount of language input provided by mothers, which differed in higher versus lower SES mothers (Hart \& Risley, 1995, 1999; Hoff-Ginsberg \& Tardif, 1995; Huttenlocher, 1999). However, other studies did not find a relationship between SES factors and child language development. Using parental report, large-scale language development studies (sample size >500) did not find a significant association between SES and vocabulary development during the second year of life (Fenson et al., 1994; Hamilton, Plunkett, \& Schafer, 2000). In the present study, we obtained parental SES data, allowing us to take parental SES factors into account.

A second factor of interest in the study was to examine the stability of language measures for individual children. Linguistic abilities undergo rapid changes during the second year of life. At 13 months most children begin to produce their first words (Benedict, 1979), at 16 months their production vocabulary size is more than 50 words (Lucariello, 1987), and by 24 months children are typically combining words (Bates, Dale, \& Thal, 1995). Previous studies have shown high variability at each age; one study with a large sample $(N=217)$ indicated that individual differences in language comprehension and production were relatively stable during the 6-month period between 13.5 and 20 months, although large variations in developmental rate existed (Fenson et al., 1994). Another study investigated language continuity in groups of late- and earlytalking toddlers and demonstrated that differences in language development were relatively stable from 
8 to 30 months at the group level (Thal, Bates, Goodman, \& Jahn-Samilo, 1997). However, performance differences between groups were not indicative of individual children. For example, Thal et al. (1997) reported that only $60 \%$ of late talkers, classified at 18 to 24 months, had been among the bottom $10 \%$ for word production at 16 months. These data suggest that additional longitudinal studies are needed to examine individual stability in language development in the second year of life.

In summary, the major goal of the present study was to test the hypothesis that speech perception in infancy is predictive of subsequent language development in the second year of life. We argue that phonetic discrimination ability is essential for normally developing young infants' acquisition of lexical information from the speech stream and therefore that better phonetic perception ability in infancy will be associated with advanced lexical development in the second year of life. A secondary focus was the stability in measures of language development between 13, 16, and 24 months of age.

\section{Participants}

The participants were 28 full-term infants (14 boys, 14 girls) tested at 6 months of age ( $M$ age $=5.92$ months, range $=5.67$ to 6.27 months). Criteria for infant participants included: (a) English as the only language spoken in the household; (b) no known physical, sensory, or mental handicap; (c) gestational age at birth at $40 \pm 3$ weeks; and (d) birth weight between 5.5 and $10 \mathrm{lb}$. An additional 6 babies were tested and eliminated for failure to reach criterion in the training stages of the HT procedure (described later). The majority of infants were White from collegeeducated parents. Infants were recruited through the database of names contained in the Infant Studies Subject Pool at the University of Washington.

\section{Procedure and Materials}

Infants were tested at 6 months of age in the HT task. At that time a family information questionnaire was used to collect data regarding the infant's general health and age, and the age, working status, and years of education of the infant's parents. The working status of each parent was coded on a 7-point scale assessing the percentage of working hours from 1 (full time) to 7 (unemployed). The three parental SES measures (age, working status, and years of education) were used in the correlational analysis to assess whether parental SES is related to infants' phonetic discrimination and later language scores. Language performance in the same children was measured with the CDI, which was completed by the parents when infants were 13,16, and 24 months of age.

At 6 months of age: Speech discrimination. Infants were tested in the HT task with computer-synthesized vowels. The goal of the study was to examine speech perception abilities using a phonetic contrast that would not produce ceiling effects, thereby masking individual differences, and one that was not strongly influenced by individual native language listening experience. The vowel contrast involved two Finnish vowels, the Finnish high-back vowel / $\mathrm{u}$ / versus the Finnish high-front / y/. Native Englishspeaking adults perceive these two vowels as closely related to the English vowels / $\mathrm{u} /$ and English /i/, respectively, and do not perceive them as foreign language vowels. Our pilot test showed that American English-speaking adults judge the vowel productions as nonprototypical instances of the English $/ \mathrm{u} /$ and /i/ vowels. We reasoned that the use of nonprototypical vowels would increase the difficulty and thus the individual differences in speech perception ability.

The $/ \mathrm{u} /$ and $/ \mathrm{y} /$ vowels used in our tests fall into the range of vowels heard by American listeners but differed from American English prototypes: The /u/ has a lower second formant $(\mathrm{F} 2=630 \mathrm{~Hz})$ than prototypical English /u/ $(\mathrm{F} 2=997 \mathrm{~Hz})$, and the /y/ has a lower first $(\mathrm{F} 1=280 \mathrm{~Hz})$ and second formant $(\mathrm{F} 2=1850 \mathrm{~Hz})$ than English /i/ $(\mathrm{F} 1=342 \mathrm{~Hz}, \mathrm{~F} 2=$ $2322 \mathrm{~Hz}$; Aaltonen \& Suonpää, 1983). The major acoustic difference between the two synthesized vowel sounds is the higher second formant in $/ y /$; the first and second formants were 255 and $1947 \mathrm{~Hz}$, respectively, for /y/, and 289 and $630 \mathrm{~Hz}$, respectively, for $/ \mathrm{u} /$. The duration of both vowels was 271 $\mathrm{ms}$ and the fundamental frequency was $120 \mathrm{~Hz}$.

During the HT procedure, the infant sat on his or her parent's lap in a sound-attenuated booth. An assistant played with toys silently on the infant's right to keep the infant's attention. On the infant's left, speech sounds were presented continuously from a studio-quality loudspeaker (Electro-Voice SP 12) at a comfortable listening level of $68 \mathrm{~dB}$ SPL. The presentation level of the speech stimuli was calibrated each day before the test with a sound-level meter (Bruel \& Kjaer Model 2203) placed in the approximate position of the infant's head. Above the loudspeaker was a Plexiglass box containing a mechanical toy that could be activated and lit; it served as the reinforcer for the infant. An experimenter observed infants' responses from the control room via a video monitor and judged HT responses, which 
were recorded by a computer (IBM 286 compatible PC). The parent and the assistant wore headphones and listened to music that masked the speech sounds so they could not influence infants' responses. The experimenter heard masking music and could barely hear the background sound, but during trials, the experimenter's headphones were totally deactivated as a further control for bias. The sound presented during trials could not be heard and the experimenter could therefore not influence performance.

Two kinds of trials, change and control, were conducted during various phases of the experiment. During change trials, the background sound, which was repeatedly played every $2 \mathrm{~s}$ during the experiment, was changed to the target sound for a 5-s period. During that period, HT responses were reinforced with a 5-s presentation of the mechanical toy (a bear pounding a drum or a monkey playing cymbals). During control trials, no sound change occurred, but infants' responses were monitored. Four outcomes are possible in the two types of trials. During change trials, an HT is correct and is scored as a hit; failure to turn is scored as a miss. During control trials, a HT response is scored as a false alarm; failure to turn is scored as a correct rejection. The background sound was $/ \mathrm{u} /$ and the target sound was $/ y /$. Only one direction of stimulus change was tested because directional effects have been observed in studies of infant speech perception (e.g., Kuhl, Stevens, et al., 2004; Polka \& Bohn, 1996); differences in performance due to directional effects could therefore have diluted the power of our assessment of individual phonetic perception.

The HT procedure consisted of three phases: conditioning, criterion, and test. In the conditioning phase, only change trials were conducted so that infants could learn the association between a change in the sound and the reinforcer. During conditioning, the target sound was presented at a louder level than the background sound ( $+4 \mathrm{~dB}$ SPL) to alert infants to the sound change. During the first conditioning trials, the reinforcer was automatically activated after two target sounds were presented so that the infant learned to pair a change in the sound with the reinforcer. After the infant made two consecutive HTs that occurred before the end of the first two presentations of the target sounds (i.e., anticipatory HTs), the intensity cue was removed. After three consecutive anticipatory HTs with no intensity cue, infants moved to the criterion phase. If the infant did not meet the conditioning criteria within 60 trials, the infant was excluded from participation in the study. The use of 60 trials ensured that as many infants as possible would be included in the study.
In the criterion phase, both change and control trials were conducted. The probability of the two types of trials was .5 with the restriction that no more than three consecutive trials of one type could occur. The criterion phase continued until 7 of 8 consecutive correct responses occurred, with a maximum of 30 trials. After meeting criterion, the test phase began. During the test phase, 30 trials, both change and control at .5 probability, were conducted. Typically, infants required two visits, approximately $20 \mathrm{~min}$ each, to complete the entire procedure, which were scheduled within 1 week. The infants typically completed the conditioning and criterion phases in the first visit and the test phase in the second visit.

At 13, 16, and 24 months of age: Language comprehension and production. The language performance of children in this longitudinal study was collected through the CDI, which has been shown to be a reliable and valid tool for assessing language and communication development from 8 to 30 months of age (Fenson et al., 2000; Fenson, et al., 1994). Two forms of the CDI-Infant and Toddler-were used in this study. The Infant form (CDI: Words and Gestures) provides norms for vocabulary comprehension, vocabulary production, and gesture production in children from 8 to 16 months of age. The Infant form consists of two parts. Part I is a 396item vocabulary checklist divided into 19 semantic categories. Ten of those categories are composed of nouns (animals, vehicles, toys, food and drink, clothing, body parts, furniture and rooms, small household items, outside things and places to go, and people). The remaining nine categories include sound effects and animal sounds, games and routines, action words, words about time, descriptive words, pronouns, question words, prepositions and locations, and quantifiers. Parents respond to each item, answering whether their child understands (and produces) each word. Part II lists gestures that are examples of nonverbal communication skills. The gestures are categorized as: early communicative gestures (intentional communication behaviors, such as giving, showing, and pointing), games and routines (social interactive gestures, such as pat-a-cake), actions with objects, pretending to be a parent, and imitating other adult actions. In the current study, the CDI Infant form was used to assess language development when children reached 13 and 16 months of age.

Language skills were assessed in 24-month-olds using the CDI Toddler form (CDI: Words and Sentences). This form is designed to measure language production in children from 16 to 30 months of age. 
This form divides language production into two major parts. Part I contains a 680 -word vocabulary production checklist composed of 22 semantic categories. Part II includes five sections designed to assess morphological and syntactic development. Two of these sections, irregular words (noun and verb) and grammatical complexity, were used in this study. The irregular word section contains a checklist of 25 irregular nouns and verbs (e.g., teeth, got). The grammatical complexity section includes 37 sentence pairs in which one exemplifies typical immature grammatical structures and the other represents more advanced structures. Three levels of grammatical ability are evaluated in this section: bound morphemes (e.g., two shoe vs. two shoes), functional words (e.g., doggie table vs. doggie on table), and early emerging complex sentences forms (e.g., turn on light vs. turn on light so I can see you). In each case, parents choose the option that typifies their child's language at a particular age.

Just before the time the child reached 13 and 16 months, parents were sent the McArthur CDI Infant form (CDI: Words and Gestures). Language comprehension was assessed in two subscales of the CDI: words understood and phrases understood. Language production was measured using the number of words produced. Nonlinguistic communicative development was quantified by the use of early gestures (intentional communication), late gestures (representational skills), and total (=early+late) gestures. Parents typically filled out the CDI on the day their infant turned the target age and returned the form within 1 week. Each parent received $\$ 10$ for mailing back a completed CDI.

Just before the children reached 24 months of age, the McArthur Toddler form (CDI: Words and Sentences) was sent to parents. Expressive language development was quantified in three subscales: word production, irregular words, and grammatical complexity. Therefore, these subscales were included in the data analysis. Each parent received \$15 for mailing back a completed CDI.

\section{Results}

\section{At 6 Months of Age: Speech Discrimination Ability}

Two quantitative measures obtained from the HT procedure were used: (a) the number of trials needed to pass the criterion phase, and (b) the overall percent correct in the test phase. Reaching criterion within a set number of trials has been used in previous HT studies to examine infant speech perception development (Werker et al., 1997; Werker \&
Tees, 1984) and has been shown to be a sensitive index of individual differences in speech perception (Lalonde \& Werker, 1995; Liu et al., 2003). In the present study, we assumed that infants who reached criterion in fewer trials were able to process speech information more efficiently than infants who needed additional trials to reach the criterion. The overall percent correct measure assessed infants' speech perception ability over the entire test period and has been frequently used in previous studies as a measure of speech discrimination performance (Goodsitt, Morse, \& ver Hoeve, 1984; Kuhl et al., 1992). The two speech perception measures were calculated for each 6-month-old infant and are shown in Table 1.

The mean percent correct $(73.61 \%)$ for all infants was well above the $50 \%$ chance level, $t(27)=11.381$, $p<.0001$, indicating that American 6-month-old infants do not experience great difficulty discriminating these vowels. No gender differences on phonetic discrimination were found; boys $(M=74.92 \%$, $S D=12.64 \%)$ and girls $(M=72.29 \%, S D=9.31 \%)$ performed equally well, $t(26)<1$. Table 1 shows that individual infants' performance was widely distributed for both of the two perceptual measures obtained at this age.

The first step in data analysis was to test whether infants' speech perception scores at 6 months were predicted by parental factors. The range in SES variables reflected our relatively homogeneous sample: maternal age $(M=32.07$ years, $S D=4.76$; range $=21$ to 40$)$, paternal age $(M=35.48$ years, $S D=6.62$; range $=22$ to 52$)$, maternal education $(M=17.1$ years, $S D=1.58$; range $=14$ to 21 ), paternal education $(M=16.1$ years, $S D=2.28$; range $=12$ to 21$)$, maternal work status (scale $=1$ to 7 , full time $=1$; $M=4.65$. $S D=1.42$; range $=3$ to 7 ), and paternal work status $(M=1.26, S D=1.14$; range $=1$ to 6$)$. No significant correlations were found between parental age and percent correct performance (mother's age, $r=.050$; father's age, $r=.349$ ), years of education (mother's education, $r=-.087$; father's education, $r=-.306$ ), or working status (mother, $r=.066$; father, $r=$.296). Similar data were obtained for the trials-tocriterion measure. In this group of middle-class

Table 1

Speech Perception Measures on 6-Month-Old Infants

\begin{tabular}{lccc}
\hline Perceptual measures & $M$ & $S D$ & Range \\
\hline Number of criterion trials & 15.18 & 7.08 & $7-29$ \\
Percent correct (\%) & 73.61 & 10.98 & $47-97$ \\
\hline
\end{tabular}


Table 2

Item and Percentile Scores of Infants on the CDI Subscales at 13 Months of Age

Phrases Words Words Early Late

understood understood produced gesture gesture

\begin{tabular}{lccrrr}
\hline Item scores & & & & & \\
$M$ & 12.70 & 93.45 & 8.10 & 10.32 & 17.58 \\
$M d n$ & 13.50 & 80.50 & 5.50 & 11.00 & 18.00 \\
$S D$ & 6.03 & 62.67 & 7.23 & 2.47 & 7.34 \\
$\quad$ Range & $4-25$ & $13-235$ & $0-23$ & $5-14$ & $5-29$ \\
Percentile scores & & & & \\
$M$ & 30.25 & 39.25 & 35.90 & 34.47 & 47.63 \\
$M d n$ & 26.50 & 38.00 & 26.50 & 35.00 & 50.00 \\
$S D$ & 20.45 & 22.35 & 21.98 & 20.55 & 25.65 \\
Range & $5-90$ & $5-93$ & $5-85$ & $5-85$ & $5-90$ \\
\hline
\end{tabular}

Note. CDI = MacArthur Communicative Development Inventory.

families, parental SES was not associated with 6month-old infants' phonetic discrimination abilities.

\section{Relation Between Speech Discrimination at 6 Months and Language at 13 Months}

Results for the 13-month-old infants are based on analysis of CDIs returned by the parents of 20 infants (boys $=10$, girls $=10$ ). Table 2 shows the item and percentile scores on the CDI subscales. Item scores are directly calculated from the number of items checked in the CDI. Percentile scores are the relative position measures of item scores based on CDI norms for boys and girls. The range of percentile scores was large (from 5\% to 93\%), though the average percentile scores of this group of children on the CDI subscales were below the normed averages for this age. The skewed percentile scores of individual infants reduce the performance differences between individuals and might reduce the proba- bility of obtaining statistically significant correlations between early speech perception and subsequent language development. Therefore, to examine fully the longitudinal relation between speech perception and language development, both item scores and percentiles were used in calculating the correlations between speech perception and language.

The relation between early speech perception and later language development was assessed using the Spearman rank order correlation analysis. Because of the relatively small sample size at each age, and the fact that the speech perception scores obtained in the HT procedure constituted relative scores along which the 20 infants were ranked, a nonparametric correlation coefficient $\left(r_{s}\right)$ was considered the statistically appropriate tool to assess these relations. Table 3 displays the correlation coefficients obtained for CDI item and percentile scores relating speech discrimination at 6 months and language performance at 13 months. Significant coefficients in Table 3 indicate the direction and strength of the relation between phonetic discrimination and CDI language subscores.

The results show that infants who require fewer trials to pass the criterion phase and achieve higher percent correct scores in the test phase have developed better lexical abilities by 13 months. The number of trials to reach criterion was highly correlated with the language comprehension subscales: phrases understood, $r_{s}($ item $)=-.662, p<.01$ and $r_{s}($ percentile $)=-.606, \quad p<.01 ;$ words understood, $r_{s}($ item $)=-.700, p<.001$ and $r_{s}($ percentile $)=-.643$, $p<.01$. The percent correct measure was significantly correlated with language production: words produced, $r_{s}($ item $)=.477, p<.05$ and $r_{s}$ (percentile $)=$ $.490, p<.05$. There were no significant correlations between parental factors and the CDI language measures at 13 months. Moreover, no significant

Table 3

Correlation Coefficients $\left(r_{s}\right)$ Relating Phonetic Discrimination at 6 Months and CDI Scores at 13 Months

\begin{tabular}{|c|c|c|c|c|c|}
\hline \multirow[b]{2}{*}{ Phonetic discrimination measures } & \multicolumn{3}{|c|}{ Language scores } & \multicolumn{2}{|c|}{ Nonlinguistic communication } \\
\hline & Phrases understood & Words understood & Words produced & Early gesture & Late gesture \\
\hline & & Item score & & & \\
\hline Criterion trials & $-.662^{* *}$ & $-.700 * * *$ & -.220 & -.339 & .072 \\
\hline \multirow[t]{2}{*}{ Percent correct } & .103 & -.047 & $.477^{*}$ & -.116 & .005 \\
\hline & & Percentile score & & & \\
\hline Criterion trials & $-.606^{* *}$ & $-.643^{* *}$ & -.199 & -.242 & .146 \\
\hline Percent correct & .135 & -.072 & $.490^{*}$ & -.059 & .046 \\
\hline
\end{tabular}

Note. $\mathrm{CDI}=$ MacArthur Communicative Development Inventory. ${ }^{*} p<.05 .{ }^{* *} p<.01 .{ }^{* * *} p<.001$. 


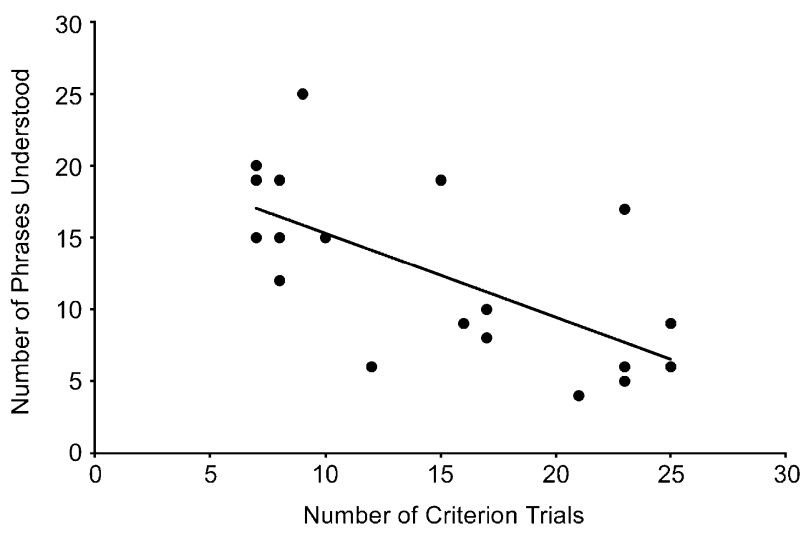

Figure 1. Relation between number of criterion trials at 6 months and number of phrases understood at 13 months $\left(r_{s}=-.662\right.$, $p<.01)$. The trend line is the least squares regression line.

correlations were found among speech discrimination measures, parental SES, and the CDI nonlinguistic communication subscales measured at 13 months, including both early and late gestures.

A regression analysis was used to assess the relative contribution of early speech perception and parental factors on later language development. A regression model with the stepwise selection method including both speech perception measures and parental SES as predictors (inclusion criterion, $p=.05$ ) revealed that the number of criterion trials contributes most to later language ability. Performance on criterion trials accounts for $44 \%, F(1,19)=14.12$, $p=.001$, and $33 \%, F(1,19)=8.91, p=.008$, of the variance in phrases understood and words understood, respectively, when item scores are used for dependent variables. No other predictors were significant independent variables in these regression models. Similar results were found when percentile scores were used in regression models. The number of criterion trials accounts for $30 \%, F(1,19)=7.71$, $p=.012$, and $33 \%, F(1,19)=8.98, p=.008$, of the variance in phrases understood and words understood, respectively. The regression models for word production did not reach statistical significance. Figures 1, 2, and 3 display the significant data relating measures of phonetic discrimination and subscales of language development at 13 months: phrases understood, words understood, and words produced, respectively.

Relation Between Speech Discrimination at 6 Months and Language at 16 Months

Results at 16 months are based on CDI forms completed by the parents of 16 infants (boys $=8$, girls $=8$ ). Table 4 shows the item and percentile

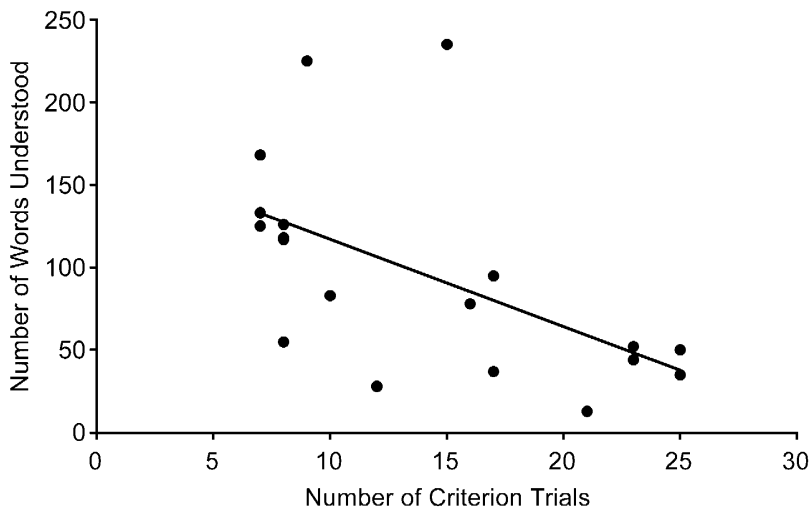

Figure 2. Relation between number of criterion trials at 6 months and number of words understood at 13 months $\left(r_{s}=-.700\right.$, $p<.001)$. The trend line is the least squares regression line.

scores of the infants on the CDI subscales. The range of percentile scores remains large (5\% to $97 \%$ ). As at 13 months of age, both item and percentile scores of the CDI subscales were employed to calculate the correlation coefficients between the perceptual measures at 6 months and language development at 16 months.

Table 5 shows the correlation coefficients $\left(r_{s}\right)$ indicating the direction and strength of the relation between phonetic discrimination at 6 months and CDI language subscales at 16 months. Figures 4 and 5 display the significant factors for data relating measures of phonetic discrimination and language development subscales at 16 months: words understood and words produced. Considering item scores of the CDI, Table 5 shows that the number of trials required to reach criterion is significantly correlated with words understood $\left(r_{s}=-.470, p<.05\right)$ and the percent correct is significantly correlated with words produced $\left(r_{s}=.470, p<.05\right)$. As shown in Table 5, no

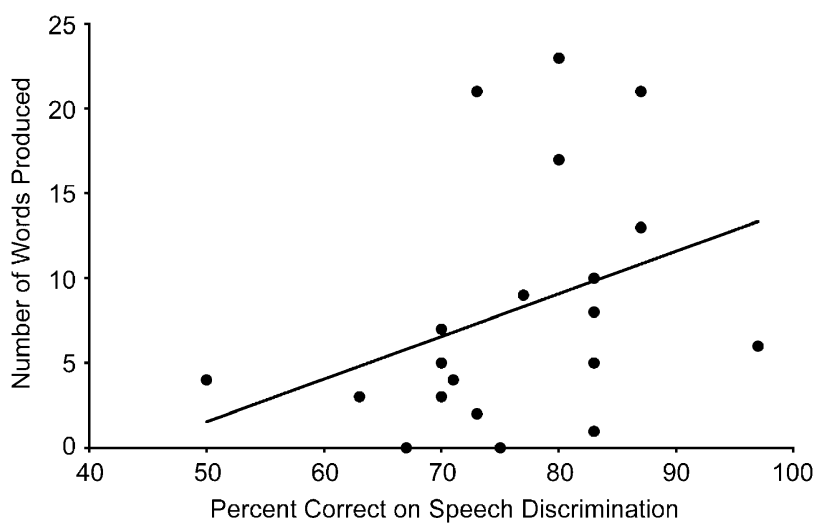

Figure 3. Relation between percent correct at 6 months and number of words produced at 13 months $\left(r_{s}=.477, p<.05\right)$. The trend line is the least squares regression line. 
Table 4

Item and Percentile Scores of CDI Subscales at 16 Months of Age

\begin{tabular}{lccccc}
\hline \multicolumn{7}{c}{$\begin{array}{c}\text { Phrases } \\
\text { understood }\end{array}$} & $\begin{array}{c}\text { Words } \\
\text { understood }\end{array}$ & $\begin{array}{c}\text { Words } \\
\text { produced }\end{array}$ & $\begin{array}{c}\text { Early } \\
\text { gesture }\end{array}$ & $\begin{array}{c}\text { Late } \\
\text { gesture }\end{array}$ \\
\hline Item score & & & & & \\
$M$ & 21.50 & 225.31 & 47.94 & 14.00 & 26.57 \\
$M d n$ & 22.50 & 234.50 & 42.00 & 14.00 & 27.00 \\
$S D$ & 4.15 & 64.45 & 44.98 & 1.88 & 8.64 \\
Range & $13-28$ & $103-324$ & $1-182$ & $11-16$ & $10-41$ \\
Percentile score & & & & \\
$M$ & 41.36 & 63.29 & 45.06 & 38.14 & 37.92 \\
$M d n$ & 41.00 & 65.00 & 46.00 & 27.50 & 20.00 \\
SD & 25.82 & 21.62 & 28.29 & 29.07 & 34.11 \\
Range & $5-90$ & $25-93$ & $5-97$ & $5-85$ & $5-95$ \\
\hline
\end{tabular}

Note. $\mathrm{CDI}=$ MacArthur Communicative Development Inventory.

significant correlations were obtained between speech perception and language development when the percentile scores of CDI subscales were used. As at 13 months of age, there was no significant association at 16 months between parental SES and CDI measures. In addition, no significant correlations were obtained at 16 months between speech discrimination and nonlinguistic measures of communication.

A regression analysis with stepwise selection method and a predictor inclusion criterion of $p=.05$ was used to assess the relative contribution of speech perception and parental factors at 6 months, and CDI language measures at 13 months, to language performance at 16 months. Phrases understood $\left(R^{2}=.33, p=.021\right)$ and words understood $\left(R^{2}=.52\right.$, $p=.002)$ at 13 months are the most powerful predictors for phrases understood and words understood at 16 months, respectively. No other predictors met the criteria for inclusion in these regression models.

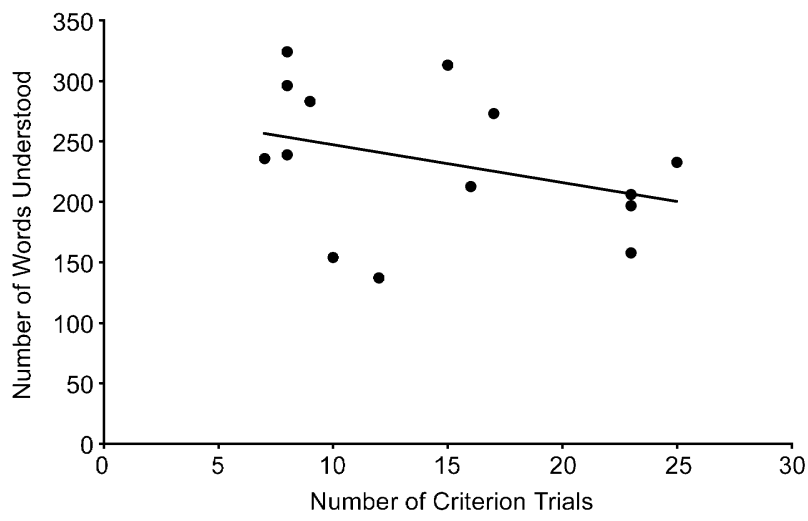

Figure 4. Relation between number of criterion trials at 6 months and number of words understood at 16 months $\left(r_{s}=-.470\right.$, $p<.05)$. The trend line is the least squares regression line.

\section{Relation Between Speech Discrimination at 6 Months and Language at 24 Months}

At 24 months, data were obtained from the parents of 13 infants (boys $=7$, girls $=6$ ) who completed the CDI Toddler form (CDI: Words and Sentences). Table 6 shows the item and percentile scores of the CDI subscales at this age. Substantial variation was again observed in percentile scores on the CDI subscales $(10 \%$ to $97 \%)$.

The correlation coefficients $\left(r_{s}\right)$ shown in Table 7 indicate the direction and strength of the relation between phonetic discrimination at 6 months and CDI language subscores at 24 months. The number of criterion trials was significantly correlated with word production, $r_{s}$ (item) $=-.480, p<.05$ and $r_{s}$ (percentile $)=-.523, p<.05$; production of irregular words, $r_{s}($ item $)=-.595, p<.05$ and $r_{s}($ percentile $)=-.592, p$ $<.05$; and grammatical complexity, $r_{s}$ (item) $=-.609, p$ $<.05$ and $r_{s}$ (percentile) $=-.570, p<.05$. Figures 6,7 , and 8 illustrate the significant correlations.

Table 5

Correlation Coefficients $\left(r_{s}\right)$ Relating Phonetic Discrimination at 6 Months and CDI Scores at 16 Months

\begin{tabular}{|c|c|c|c|c|c|}
\hline \multirow[b]{2}{*}{ Phonetic discrimination measures } & \multicolumn{3}{|c|}{ Language scores } & \multicolumn{2}{|c|}{ Nonlinguistic communication } \\
\hline & Phrases understood & Words understood & Words produced & Early gesture & Late gesture \\
\hline \multicolumn{6}{|c|}{ Item score } \\
\hline Criterion trials & -.237 & $-.470^{*}$ & -.096 & -.009 & .220 \\
\hline Percent correct & .129 & -.170 & $.470 *$ & -.093 & -.197 \\
\hline \multicolumn{6}{|c|}{ Percentile score } \\
\hline Criterion trials & -.088 & -.030 & .226 & .272 & .381 \\
\hline Percent correct & -.080 & -.162 & .409 & .019 & -.072 \\
\hline
\end{tabular}

Note. CDI $=$ MacArthur Communicative Development Inventory.

${ }^{*} p<.05$. 


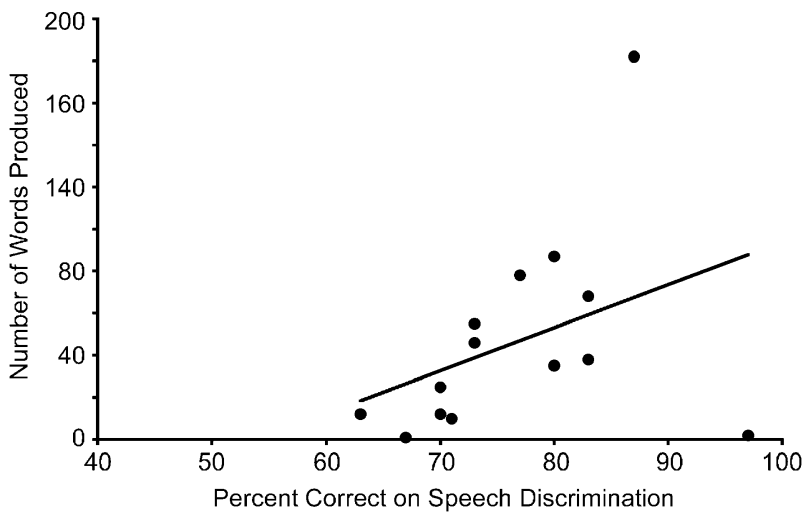

Figure 5. Relation between percent correct at 6 months and number of words produced at 16 months $\left(r_{s}=.470, p<.05\right)$. The trend line is the least squares regression line.

The regression model with stepwise selection method including the speech perception measures, percentile scores of CDI language measures at 13 and 16 months of age, and parental SES factors as independent variables demonstrates that the speech perception measure, the number of criterion trials, is the most important predictor for lexical production at 24 months. It accounts for $31 \%, F(1,12)=4.85$, $p=.050$, of the percentile score variances in word production. Using the same predictors in the regression analysis, the number of criterion trials is also the most powerful predictor $\left(R^{2}=.43, p=.009\right)$ in a regression model that accounts for $61 \%$ of the percentile score variances in irregular words produced, $F(2$, $12)=7.91, p=.009$. The mother's working status $\left(R^{2}=.18, p=.056\right)$ reached marginal significance at 24 months. When using item scores, a regression model using the same predictors accounts for $66 \%$, $F(2,12)=9.50, p=.005$, of the variance in the pro-

Table 6

Item and Percentile Scores of CDI Subscales at 24 Months of Age

\begin{tabular}{lccc}
\hline & $\begin{array}{c}\text { Words } \\
\text { produced }\end{array}$ & $\begin{array}{c}\text { Production of } \\
\text { irregular words }\end{array}$ & $\begin{array}{c}\text { Grammatical } \\
\text { complexity }\end{array}$ \\
\hline $\begin{array}{l}\text { Item score } \\
M\end{array}$ & 374.38 & 5.92 & 12.46 \\
$M d n$ & 391.00 & 4.00 & 10.00 \\
SD & 128.98 & 4.94 & 10.45 \\
Range & $125-593$ & $1-20$ & $1-29$ \\
Percentile score & & & \\
$M$ & 60.31 & 54.92 & 63.00 \\
Mdn & 60.00 & 57.50 & 67.00 \\
SD & 17.96 & 22.36 & 24.36 \\
Range & $25-93$ & $25-97$ & $10-93$ \\
\hline
\end{tabular}

Note. $\mathrm{CDI}=$ MacArthur Communicative Development Inventory. duction of irregular words. The number of criterion trials $\left(R^{2}=.35, p=.012\right)$ is again the most powerful predictor; mother's working status $\left(R^{2}=.31\right.$, $p=.014)$ is the second most important predictor. No other predictors met the criteria for inclusion in the regression models for grammatical complexity. The results of various regression models consistently demonstrate that early speech perception is an important predictor of later language development.

\section{Relations Among CDI Subscales}

Analyses were also conducted to examine the relations among the various subscales of the CDI. Tables 8 and 9 show correlations $\left(r_{s}\right)$ among 13-, 16-, and 24-month CDI subscales with item and percentile scores, respectively. High internal consistency was found for the two subscales of the CDI on language comprehension, phrases and words understood. The two subscales were strongly correlated with each other at 13 months, $r_{\mathrm{s}}($ item $)=.833, p<.001$ and $r_{s}$ (percentile) $=.822, p<.001$, and 16 months, $r_{s}($ item $)=.716, \quad p<.001$ and $r_{s}($ percentile $)=.686$, $p<.01$. At 24 months, similar consistency was shown for language production among CDI subscales. Words produced was highly associated with production of irregular words, $r_{s}$ (item) $=.844, p<.001$ and $r_{s}$ (percentile $)=.899, p<.001$, and grammatical complexity, $r_{s}($ item $)=.789, p<.001$ and $r_{s}$ (percentile) $=.720, p<.01$. Irregular word production was significantly correlated with grammatical complexity, $r_{s}($ item $)=.652, p<.01$ and $r_{s}($ percentile $)=.670$, $p<.01$. Beyond the domain of language, significant correlations also indicate high internal consistency between two nonverbal communication subscales, early and late gestures, at 13 months, $r_{\mathrm{s}}$ (item) $=.470$, $p<.05$ and $r_{s}$ (percentile) $=.554, p<.01$, and 16 months, $r_{\mathrm{s}}($ item $)=.618, p<.01$ and $r_{s}($ percentile $)=$ $.664, p<.01$.

Although high internal consistency is repeatedly shown within various CDI subscales when measuring the same communication dimension at different ages, few significant correlations are shown among subscales measuring different communication aspects. At both 13 and 16 months, no significant correlation was found between the comprehension and production subscales of the CDI except when the percentile scores were used to examine this relation at 13 months. It is interesting that the early gesture subscale score is significantly correlated with two subscales of language comprehension, words understood and phrases understood, at both 13 months: phrases understood, $r_{s}($ item $)=.564, p<.01$ and $r_{s}($ percentile $)=.473, p<.05$; words understood, 
Table 7

Correlation Coefficients $\left(r_{s}\right)$ of Phonetic Discrimination Measures at 6 Months and CDI Language Scores at 24 Months

\begin{tabular}{lccc}
\hline & \multicolumn{3}{c}{$\begin{array}{c}\text { Language } \\
\text { scores }\end{array}$} \\
\cline { 2 - 4 } $\begin{array}{l}\text { Phonetic } \\
\text { discrimination } \\
\text { measures }\end{array}$ & $\begin{array}{c}\text { Word } \\
\text { produced }\end{array}$ & $\begin{array}{c}\text { Production of } \\
\text { irregular words }\end{array}$ & $\begin{array}{c}\text { Grammatical } \\
\text { complexity }\end{array}$ \\
\hline & \multicolumn{3}{c}{ Item score } \\
Criterion trials & $-.480^{*}$ & $-.595^{*}$ & $-.609 *$ \\
Percent correct & .050 & .210 & .240 \\
\cline { 2 - 4 } & \multicolumn{3}{c}{ Percentile score } \\
Criterion trials & $-.523^{*}$ & $-.592^{*}$ & $-.570^{*}$ \\
Percent correct & .090 & .203 & .246 \\
\hline
\end{tabular}

Note. $\mathrm{CDI}=$ MacArthur Communicative Development Inventory. * $p<.05$.

$r_{s}($ item $)=.611, \quad p<.01 \quad$ and $\quad r_{s}($ percentile $)=.550$, $p<.01$; and at 16 months: phrases understood, $r_{s}(\mathrm{i}-$ tem $)=.714, p<.01$ and $r_{s}($ percentile $)=.636, p<.01$; words understood, $r_{s}$ (item) $=.620, \quad p<.01$ and $r_{s}($ percentile $)=.749, p<.001$. However, the late gesture scale is not significantly correlated with language comprehension subscales except for phrases understood at 16 months, $r_{s}$ (item) $=.499, p<.05$ and $r_{s}($ percentile $)=.467, p<.05$.

Language Stability Over Time: Relations Among 13-, 16-, and 24-Month Data

One advantage of using a psychometrically equivalent tool, such as the CDI, is that the results allow one to explore an individual child's language stability over time. Developmental stability can be assessed in 13- and 16-month-old children for all

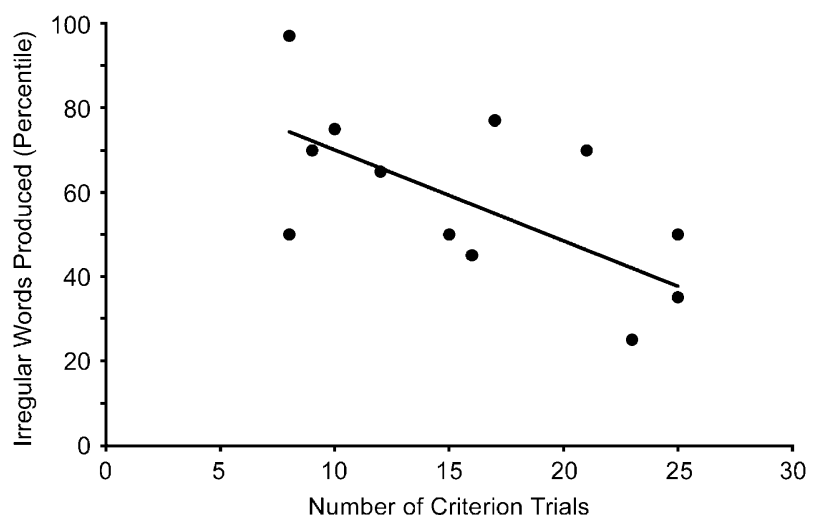

Figure 6. Relation between number of criterion trials at 6 months and percentile of words produced at 24 months $\left(r_{s}=-.523\right.$, $p<.05)$. The trend line is the least squares regression line.

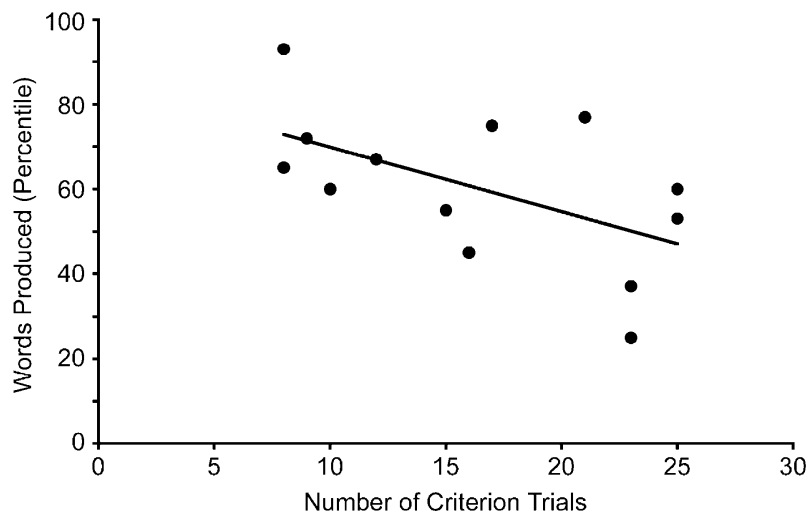

Figure 7. Relation between number of criterion trials at 6 months and percentile of irregular word production at 24 months $\left(r_{s}=\right.$ $-.592, p<.05)$. The trend line is the least squares regression line.

subscales of the CDI. Because a different form of the CDI was used at 24 months, only the words produced subscale can be used at that age to assess stability.

Significant correlations were obtained for all CDI subscales between 13 and 16 months, as shown in Tables 8 and 9 . For example, performance on phrases understood, $r_{s}($ item $)=.591, p<.01$ and $r_{s}$ (percentile $)=.523, p<.05$, and words produced, $r_{s}($ item $)=$ $.566, p<.05$ and $r_{s}$ (percentile $)=.480, p<.05$, are significantly related at these two ages. Associations between 13 and 16 months are stronger when item scores in CDI subscales, rather than percentile scores, are used to calculate the coefficients. In contrast, no significant correlation was obtained between 13- or 16-month performance and 24-month performance on word production. These results indicate that individual differences in language development are stable from 13 to 16 months in both expressive and receptive aspects of language. Results showing con-

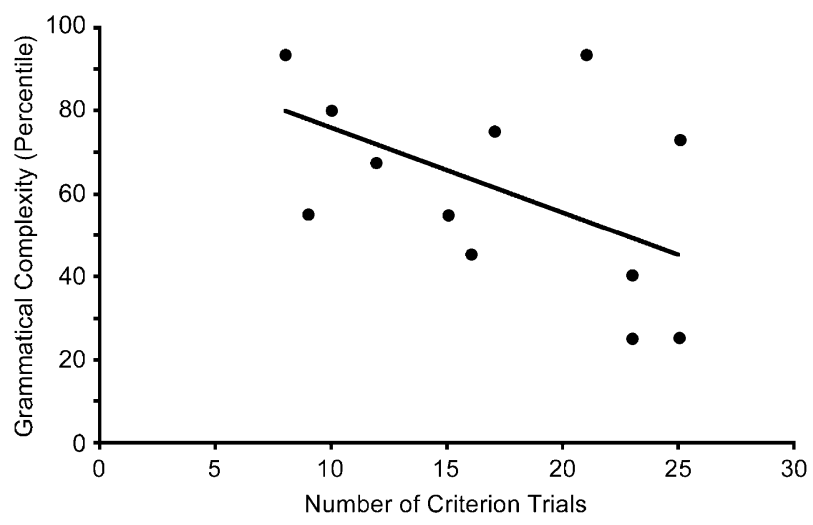

Figure 8. Relation between number of criterion trials at 6 months and percentile of grammatical complexity at 24 months $\left(r_{s}=\right.$ $-.570, p<.05)$. The trend line is the least squares regression line. 
Table 8

Correlation Coefficient (Spearman's $r_{s}$ ) Matrix for Item Scores Among CDI Subscales at 13, 16, and 24 Months

\begin{tabular}{|c|c|c|c|c|c|c|c|c|c|c|c|c|c|}
\hline CDI subscales (Percentile score) & 1 & 2 & 3 & 4 & 5 & 6 & 7 & 8 & 9 & 10 & 11 & 12 & 13 \\
\hline \multicolumn{14}{|l|}{ 1. Phrases understood -13 months } \\
\hline 2. Words understood -13 months & $.833^{* * *}$ & & & & & & & & & & & & \\
\hline 3. Words produced -13 months & .307 & .373 & & & & & & & & & & & \\
\hline 4. Early gesture -13 months & $.564^{* *}$ & $.611^{* *}$ & .171 & & & & & & & & & & \\
\hline 5. Late gesture -13 months & .155 & .049 & .058 & $.470^{*}$ & & & & & & & & & \\
\hline 6. Phrases understood -16 months & $.591^{* *}$ & $.547^{*}$ & -.125 & $.470^{*}$ & .255 & & & & & & & & \\
\hline 7. Words understood -16 months & $.619^{* *}$ & $.789^{* * *}$ & * .099 & .432 & -.066 & $.716^{* * *}$ & & & & & & & \\
\hline 8. Words produced -16 months & -.118 & -.053 & $.566^{*}$ & .007 & .081 & .039 & .218 & & & & & & \\
\hline 9. Early gesture - 16 months & .227 & .272 & .056 & $.642^{* *}$ & .380 & $.714^{* *}$ & $.620^{* *}$ & .329 & & & & & \\
\hline 10. Late gesture -16 months & -.020 & -.064 & -.259 & $.488^{*}$ & $.851^{* * *}$ & $.499 *$ & .121 & .166 & $.618^{* *}$ & & & & \\
\hline 11. Words produced -24 months & .066 & .135 & .063 & .014 & -.247 & .229 & .482 & .436 & $.607^{*}$ & -.101 & & & \\
\hline $\begin{array}{l}\text { 12. Irregular words produced } \\
-24 \text { months }\end{array}$ & .126 & .246 & .235 & .055 & -.190 & .065 & .299 & .520 & .365 & -.093 & $.844^{* * *}$ & & \\
\hline $\begin{array}{l}\text { 13. Grammatical complexity } \\
-24 \text { months }\end{array}$ & .197 & .211 & .051 & .079 & .163 & .171 & .384 & .393 & $.639^{*}$ & -.014 & $.789^{* * *}$ & $.652^{* *}$ & \\
\hline
\end{tabular}

Note. $\mathrm{CDI}=$ MacArthur Communicative Development Inventory.

${ }^{*} p<.05 .{ }^{* *} p<.01 .{ }^{* * *} p<.001$.

tinuity over a 6-month period in language ability have been reported in other studies using the CDI (Fenson et al., 1994; Thal et al., 1997). Fenson et al. (1994) used a larger group $(N=217)$ to examine language stability between 13.5 and 20 months and obtained a correlation coefficient of $r=.69$ on word production. The examined periods in the present study, 8 and 11 months, are considerably longer than those used by Fenson et al. Thal et al. (1997) reported great developmental variability between 16 and 24 months, consistent with the present findings, indicating that individual differences in word production development do not remain stable during the second year of life.

\section{Discussion}

The present study was designed to test whether infants' performance on a standard measure of speech perception in the first year of life significantly

Table 9

Correlation Coefficient (Spearman's $r_{s}$ ) Matrix for Percentile Scores Among CDI Subscales at 13, 16, and 24 Months

\begin{tabular}{|c|c|c|c|c|c|c|c|c|c|c|c|c|c|}
\hline CDI subscales (Percentile score) & 1 & 2 & 3 & 4 & 5 & 6 & 7 & 8 & 9 & 10 & 11 & 12 & 13 \\
\hline \multicolumn{14}{|l|}{ 1. Phrases understood -13 months } \\
\hline 2. Words understood -13 months & $.822^{* * *}$ & & & & & & & & & & & & \\
\hline 3. Words produced -13 months & .346 & $.381^{*}$ & & & & & & & & & & & \\
\hline 4. Early gesture-13 months & $.473^{*}$ & $.550 * *$ & .183 & & & & & & & & & & \\
\hline 5. Late gesture -13 months & .166 & .014 & .067 & $.554^{* *}$ & & & & & & & & & \\
\hline 6. Phrases understood - 16 months & $.523^{*}$ & $.440^{*}$ & -.164 & .437 & .383 & & & & & & & & \\
\hline 7. Words understood -16 months & .340 & $.518^{*}$ & .129 & .398 & .254 & $.686^{* *}$ & & & & & & & \\
\hline 8. Words produced -16 months & -.222 & -.117 & $.480^{*}$ & $=.040$ & .256 & -.043 & .310 & & & & & & \\
\hline 9. Early gesture- -16 months & .063 & .037 & .025 & $.497^{*}$ & $.474^{*}$ & $.636^{* *}$ & $.749^{* * *}$ & .372 & & & & & \\
\hline 10. Late gesture -16 months & -.065 & -.196 & -.186 & $.475^{*}$ & $.924^{* * *}$ & $.467^{*}$ & .420 & .424 & $.664^{* *}$ & & & & \\
\hline 11. Words produced -24 months & .000 & .069 & -.081 & -.101 & -.312 & .169 & .364 & .196 & .324 & .009 & & & \\
\hline $\begin{array}{l}\text { 12. Irregular words produced } \\
-24 \text { months }\end{array}$ & .088 & .202 & .213 & -.045 & -.307 & .057 & .217 & .233 & .200 & .095 & $.899^{* * *}$ & & \\
\hline $\begin{array}{l}\text { 13. Grammatical complexity } \\
-24 \text { months }\end{array}$ & .122 & .113 & .008 & -.073 & -.322 & .018 & .229 & .215 & .452 & -.042 & $.720^{* *}$ & $.670^{* *}$ & \\
\hline
\end{tabular}

Note. $\mathrm{CDI}=$ MacArthur Communicative Development Inventory. ${ }^{*} p<.05 .{ }^{* *} p<.01 .{ }^{* * *} p<.001$. 
predicted their language abilities at three later points in development. The hypothesis was confirmed. The results of the study demonstrated significant correlations between individual infants' speech perception skills at 6 months and their language abilities at 13, 16, and 24 months. The results demonstrated, for the first time, that a speech perception measure at 6 months of age - the ability to discriminate two vowels as measured by the HT conditioning technique - significantly predicts language outcomes at three ages over the next 18 months.

Previous retrospective studies suggested a potential connection between brain responses to speech syllables in newborns and the classification of those children at 3,5, and 8 years into groups having high versus low language skills (Molfese, 2000; Molfese \& Molfese, 1985, 1997). Taken together, the results suggest that phonetic perception may play an important role in language acquisition.

A secondary goal was to examine the continuity in measures of language development over time. The results suggest that individual differences in language development are stable from 13 to 16 months in both expressive and receptive aspects of language. However, between either 13 or 16 months and 24 months, the results on word production show a lack of stability. The lack of developmental stability between 13 or 16 months and 24 months shown in this study is similar to previous findings for this period (Feldman et al., 2000; Thal et al., 1997), suggesting increasing variation in individual lexical development between the first and second birthdays.

\section{Explaining the Link Between Phonetic Discrimination and Language Development}

The present results demonstrate a predictive relation between early speech perception performance and later language. The caveat, of course, is that a causal relation between early speech perception and later language performance cannot be established with the correlation approach used in the present experiment. The question is: Is it speech perception, or some other factor, that links early speech perception performance and later language?

There are two obvious mediating factor accounts. Each one argues that it is not infants' phonetic skills per se that explain the observed association between early speech and later language. Considering the first, a historical view might argue that a unified language faculty, one that varies genetically in the population (Fodor, 1983; Pinker, 1994), explains the results. A unified language faculty could exhibit itself both in variation in 6-month-old infants' pho- netic perception and in that child's more complex later language skills. If a unified language faculty exists, one could not argue that phonetic perception is associated with lexical or grammatical language performance, they would be one and the same thing. Epidemiological studies showing a genetically related factor in language disorders that affects multiple levels provide supportive data for this view (Dale et al., 1998; Flint, 1999; Lai, Fisher, Hurst, VarghaKhadem, \& Monaco, 2001). On this account, a 6-month-old's skills at phonetic discrimination should predict that same child's language skills much later because both reflect the same capacity for language learning.

A second mediating factor account is that the association we have observed between speech perception and later language relies on infants' more general cognitive or sensory abilities rather than on their phonetic abilities per se. Cognitive factors, such as attention and learning, could be argued to play a role, for example, especially when measured using complex tasks such as HT conditioning, a task that taps general cognitive abilities (Kuhl, 1985; Polka et al., 1995). The HT task requires infants to learn a complex contingency between two independent events, a change in a sound with the presentation of a reward. Infants with higher cognitive skills may therefore perform better in the HT task, independent of their phonetic abilities. Cognitive factors may also play a role in learning the arbitrary pairing of sound patterns and words. Some evidence in support of cognitive factors is the fact that among the two measures chosen to assess infant phonetic discrimination, number of criterion trials was a better predictor than percent correct. The number of criterion trials taps the rapidity with which infants make the correct association and could rely on infant's cognitive abilities, as well as on their capacity to respond to phonetic differences. No studies have attempted to assess speech perception, when measured in the HT task, and cognitive skills in the same infants. It is possible that cognitive abilities play a role.

Infants' sensory abilities might similarly be argued to explain the observed association between phonetic perception and later language. Group studies suggest that poor auditory perceptual skills, when measured using both speech and nonspeech signals, is a significant factor in children who have difficulty with language and reading (Tallal, 1980; Tallal et al., 1996; Tallal, Stark, \& Mellits, 1985). Children with SLI use fewer spectral cues to segregate a target tone from a masking noise when compared with normal controls (Wright et al., 1997). In a recent study of 6-month-old infants with and with- 
out positive histories of language impairment, auditory temporal resolution thresholds of individual infants for nonspeech stimuli were associated with language comprehension and production scores at age 2 (Benasich \& Tallal, 2002). These results suggest that the observed variability in typically developing infants' phonetic processing abilities, those critical for language development, could be influenced by variation in infants' complex auditory abilities.

The current study cannot definitively rule out these alternative explanations. However, it is also clear that there is a potential advantage afforded a child whose abilities to discern differences between phonetic events are advanced. Exposure to ambient language causes a perceptual transition from a language-general pattern of speech perception to a language-specific pattern (Best, McRoberts, LaFleur, \& Silver-Isenstadt, 1995; Kuhl et al., 1992; Werker \& Tees, 1984). Advanced speech discrimination skills would allow more efficient detection of the statistical regularities in ambient speech (Goodsitt et al., 1993; Saffran, 2001; Saffran et al., 1996), and this would move infants to the native language listening pattern earlier in development. Native language listening affords an advantage because native language words use language-specific phonology. Better phonetic perception assists the detection of phonotactic patterns in speech (Jusczyk, Luce, \& Charles-Luce, 1994), which may in turn allow infants to accelerate their discovery of words in running speech and, eventually, to advance their word production. In other words, infants who are more skilled in detecting phonetic differences may simply progress faster on the ladder toward language. Advanced phonetic abilities in infancy may bootstrap language learning at higher levels (Morgan \& Demuth, 1996), propelling infants to more sophisticated levels earlier in development. However, infants' sensory and cognitive skills may also play a role, either independently or in concert with infants' phonetic skills.

To separate the two general mediating factor explanations - the integrated language faculty explanation and general cognitive and sensory abilities explanation from our proposed hypothesis (that the ability to discriminate phonetic units plays a decisive role in language learning) - additional longitudinal studies will need to be conducted. In such studies, early linguistic, cognitive, social, and sensory factors could be assessed in the same population of infants, with the goal of examining the intercorrelations and predictive value of the early measures for later language development.

Toward that end, we have begun a longitudinal study following 40 children from 6 months to 3 years, assessing infants' performance on auditory, phonetic, babbling, and other tasks, and relating these early skills to language outcomes. Of interest to the present discussion, phonetic perception was assessed using the same vowel stimuli and HT discrimination task used in the present study. Preliminary analyses of the language outcome measures at 24 months confirm, with a much larger sample, the strong and significant association between early phonetic perception and later language reported here. Analysis of the entire study will eventually reveal the patterns of association between and among the various predictor measures.

We ascribe to the view that multiple attentional, social, and linguistic cues contribute to infants' word understanding and production in early language development (Hirsh-Pasek \& Golinkoff, 1996; Hollich, Hirsh-Pasek, \& Golinkoff, 2000), and therefore expect that large-scale studies of the type just described will show a complex pattern in predicting later language. The contribution of the current study is that it demonstrates, for the first time, that performance on a standard measure of speech perception at 6 months reliably predicts language scores at 2 years in a population of typically developing children. The current study serves as an initial test of the hypothesis that infants' early speech perception abilities play a significant role in their later language development. As discussed, however, this result leaves open several possibilities regarding the role that sensory and cognitive skills may play in the observed association.

\section{Implications for the Early Identification of Language- Related Difficulties}

The results of this study, showing significant correlations between infants' speech perception at 6 months and language performance as long as 18 months later, may eventually have clinical implications for the early identification of language-related difficulties. Further research is needed, but it is possible that phonetic sensitivity measures might be employed as one of the early identification tools at 6 months to screen infants at high risk for later speech and language difficulties, such as SLI, reading disability, or phonological disorders. Several studies have reported that children who were late talkers at 24 months were likely to be delayed in expressive language development 1 year later (Paul, 1991; Paul \& Smith, 1993; Rescorla, Roberts, \& Dahlsgaard, 1997; Rescorla \& Schwartz, 1990). Significant correlations between 6-month-olds' phonetic discrimination abilities and 24-month-olds' language performance 
found here could eventually lead to diagnostic tests for at risk populations.

\section{Conclusions}

The present study demonstrates that a standard measure of speech perception taken at 6 months of age in a population of typically-developing childrenthe discrimination of two simple vowels - predicts language development at 13,16 , and 24 months of age. These findings have both theoretical and practical value. From a theoretical standpoint, the findings are consistent with the idea that phonetic perception plays a critical role in the early phases of language acquisition. Practically, the results suggest the possibility that early measures of speech discrimination may provide information helpful to the early detection of infants at risk for language difficulties.

\section{References}

Aaltonen, O., \& Suonpää, J. (1983). Computerized twodimensional model for Finnish vowel identifications. Audiology, 22, 410-415.

Adlard, A., \& Hazan, V. (1998). Speech perception in children with specific reading difficulties (dyslexia). Quarterly Journal of Experimental Psychology, 51A, 153-177.

Aldridge, M. A., Stillman, R. D., \& Bower, T. G. R. (2001). Newborn categorization of vowel-like sounds. Developmental Science, 4, 220-232.

Bates, E., Dale, P., \& Thal, D. (1995). Individual differences and their implications for theories of language development. In P. Fletcher \& B. MacWhinney (Eds.), The handbook of child language (pp. 96-151). Oxford, England: Blackwell.

Benasich, A. A., \& Tallal, P. (2002). Infant discrimination of rapid auditory cues predicts later language impairment. Behavioural Brain Research, 136, 31-49.

Benedict, H. (1979). Early lexical development: Comprehension and production. Journal of Child Language, 6, $183-200$.

Best, C. T., McRoberts, G. W., LaFleur, R., \& SilverIsenstadt, J. (1995). Divergent developmental patterns for infants' perception of two nonnative consonant contrasts. Infant Behavior and Development, 18, 339-350.

Bornstein, M. H., Haynes, M. O., \& Painter, K. M. (1998). Sources of child vocabulary competence: A multivariate model. Journal of Child Language, 25, 367-393.

Bradlow, A. R., Kraus, N., Nicol, T. G., McGee, T. J., Cunningham, J., \& Zecker, S. G., et al. (1999). Effects of lengthened formant transition duration on discrimination and neural representation of synthetic CV syllables by normal and learning-disabled children. Journal of the Acoustical Society of America, 106, 2086-2096.

Dale, P. S., Simonoff, E., Bishop, D. V. M., Eley, T. C., Oliver, B., \& Price, T. S., et al. (1998). Genetic influence on language delay in two-year-old children. Nature Neuroscience, 1, 324-328.

Eimas, P. D. (1974). Auditory and linguistic processing of cues for place of articulation by infants. Perception and Psychophysics, 16, 513-521.

Eimas, P. D. (1975). Auditory and phonetic coding of the cues for speech: Discrimination of the [r-l] distinction by young infants. Perception and Psychophysics, 18, 341-347.

Eimas, P. D., Siqueland, E. R., Jusczyk, P., \& Vigorito, J. (1971). Speech perception in infants. Science, 171, 303-306.

Feldman, H. M., Dollaghan, C. A., Campbell, T. F., KursLasky, M., Janosky, J. E., \& Paradise, J. L. (2000). Measurement properties of the MacArthur Communication Development Inventories at ages one and two years. Child Development, 71, 310-322.

Fenson, L., Bates, E., Dale, P., Goodman, J., Reznick, J. S., \& Thal, D. (2000). Measuring variability in early child language: Don't shoot the messenger. Child Development, $71,323-328$.

Fenson, L., Dale, P., Reznick, J. S., Bates, E., Thal, D., \& Pethick, S. (1994). Variability in early communicative development. Monographs of the Society for Research in Child Development, 59, (5, Serial No. 242).

Ferguson, C. A., Menn, L., \& Stoel-Gammon, C. (Eds.). (1992). Phonological development: Models, research, implications. Timonium, MD: York Press.

Flint, J. (1999). The genetic basis of cognition. Brain, 122, 2015-2031.

Fodor, J. (1983). The modularity of mind. Cambridge, MA: MIT Press.

Friederici, A. D., \& Wessles, J. M. I. (1993). Phonotactic knowledge of word boundaries and its use in infant speech perception. Perception and Psychophysics, 54, 287-295.

Godfrey, J. J., Syrdal-Lasky, A. K., Millay, K., \& Knox, C. M. (1981). Performance of dyslexic children on speech perception tests. Journal of Experimental Child Psychology, $32,401-424$.

Goodsitt, J. V., Morgan, J. L., \& Kuhl, P. K. (1993). Perceptual strategies in prelingual speech segmentation. Journal of Child Language, 20, 229-252.

Goodsitt, J. V., Morse, P. A., \& ver Hoeve, J. N. (1984). Infant speech recognition in multisyllabic contexts. Child Development, 55, 903-910.

Hamilton, A., Plunkett, K., \& Schafer, G. (2000). Infant vocabulary development assessed with a British communicative development inventory. Journal of Child Language, 27, 689-705.

Hart, B., \& Risley, T. (1995). Meaningful differences in the everyday experience of young American children. Baltimore: Brookes.

Hart, B., \& Risley, T. (1999). The social world of children learning to talk. Baltimore: Brookes.

Hirsh-Pasek, K., \& Golinkoff, R. M. (1996). The origins of grammar: Evidence from early language comprehension. Cambridge, MA: MIT Press.

Hoff-Ginsberg, E., \& Tardif, T. (1995). Socicoeconomic status and parenting. In M. H. Bornstein (Ed.), Handbook of parenting (Vol. 2, pp. 161-188). Hillsdale, NJ: Erlbaum. 
Hollich, G. J., Hirsh-Pasek, K., \& Golinkoff, R. M. (2000). Breaking the language barrier: An emergentist coalition model for the origins of word learning. Monographs of the Society for Research in Child Development, 65, (3, Serial No. 262).

Hurford, D. P., \& Sanders, R. E. (1990). Assessment and remediation of a phonemic discrimination deficit in reading disabled second and fourth graders. Journal of Experimental Child Psychology, 50, 396-415.

Huttenlocher, J. (1999). Language input and language growth. In N. A. Fox, L. A. Leavitt, \& J. G. Warhol (Eds.), The role of early experience in infant development (pp. 6982). Calverton, NY: Johnson \& Johnson Pediatric Institute.

Jusczyk, P. W. (1997). The discovery of spoken language. Cambridge, MA: MIT Press.

Jusczyk, P. W., Luce, P. A., \& Charles-Luce, J. (1994). Infants' sensitivity to phonotactic patterns in the native language. Journal of Memory and Language, 33, 630-645.

Kraus, N., McGee, T. J., Carrell, T. D., Zecker, S. G., Nicol, T. G., \& Koch, D. B. (1996). Auditory neurophysiologic responses and discrimination deficits in children with learning problems. Science, 273, 971-973.

Kuhl, P. K. (1979). Speech perception in early infancy: Perceptual constancy for spectrally dissimilar vowel categories. Journal of the Acoustical Society of America, 66, $1668-1679$.

Kuhl, P. K. (1983). Perception of auditory equivalence classes for speech in early infancy. Infant Behavior and Development, 6, 263-285.

Kuhl, P. K. (1985). Methods in the study of infant speech perception. In G. Gottlieb \& N. A. Krasnegor (Eds.), Measurement of audition and vision in the first year of life: $A$ methodological overview (pp. 223-251). Norwood, NJ: Ablex.

Kuhl, P. K. (2000). A new view of language acquisition. Proceedings of the National Academy of Sciences, USA, 97, $11850-11857$.

Kuhl, P. K., Stevens, E., Hayashi, A., Deguchi, T., Kiritani, S., \& Iverson, P. (2004). Mechanisms underlying developmental change in infants' perception of speech. Manuscript submitted for publication.

Kuhl, P. K., Tsao, F. M., \& Liu, H. M. (2003). Foreign-language experience in infancy: Effects of short-term exposure and social interaction on phonetic learning. Proceedings of the National Academy of Sciences, USA, 100, 9096-9101.

Kuhl, P. K., Williams, K. A., Lacerda, F., Stevens, K. N., \& Lindblom, B. (1992). Linguistic experience alters phonetic perception in infants by 6 months of age. Science, 255, 606-608.

Lai, C. S. L., Fisher, S. E., Hurst, J. A., Vargha-Khadem, F., \& Monaco, A. P. (2001). A forkhead-domain gene is mutated in a severe speech and language disorder. Nature, $413,519-523$.

Lalonde, C. E., \& Werker, J. F. (1995). Cognitive influence on cross-language speech perception in infancy. Infant Behavior and Development, 18, 459-475.
Leonard, L. B., McGregor, K. K., \& Allen, G. D. (1992). Grammatical morphology and speech perception in children with specific language impairment. Journal of Speech and Hearing Research, 35, 1076-1085.

Liu, H. M., Kuhl, P. K., \& Tsao, F. M. (2003). An association between mothers' speech clarity and infants' speech discrimination skills. Developmental Science, 6, F1-F10.

Lucariello, J. (1987). Concept formation and its relations to word learning and use in the second year. Journal of Child Language, 14, 309-332.

Manis, F. R., McBride-Chang, C., Seidenberg, M. S., Keating, P., Doi, L. M., \& Munson, B., et al. (1997). Are speech perception deficits associated with developmental dyslexia? Journal of Experimental Child Psychology, 66, $211-235$.

Mattys, S. L., Jusczyk, P. W., Luce, P. A., \& Morgan, J. L. (1999). Phonotactic and prosodic effects on word segmentation in infants. Cognitive Psychology, 38, 465-494.

Maye, J., Werker, J. F., \& Gerken, L. (2002). Infant sensitivity to distributional information can affect phonetic discrimination. Cognition, 82, B101-111.

Molfese, D. L. (2000). Predicting dyslexia at 8 years of age using neonatal brain responses. Brain and Language, 72 , $238-245$.

Molfese, D. L., \& Molfese, V. J. (1985). Electrophysiological indices of auditory discrimination in newborn infants: The bases for predicting later language development? Infant Behavior and Development, 8, 197-211.

Molfese, D. L., \& Molfese, V. J. (1997). Discrimination of language skills at five years of age using event-related potentials recorded at birth. Developmental Neuropsychology, 13, 135-156.

Morgan, J. L., \& Demuth, K. D. (Eds.). (1996). Signal to syntax: Bootstrapping from speech to grammar in early language acquisition. Mahwah, NJ: Erlbaum.

Paul, R. (1991). Profiles of toddlers with slow expressive language development. Topics in Language Disorders, 11, $1-13$.

Paul, R., \& Smith, R. L. (1993). Narrative skills in 4-year-olds with normal, impaired, and late-developing language. Journal of Speech and Hearing Research, 36, 592-598.

Pinker, S. (1994). The language instinct. New York: HarperCollins.

Polka, L., \& Bohn, O.-S. (1996). A cross-language comparison of vowel perception in English-learning and German-learning infants. Journal of the Acoustical Society of America, 100, 577-592.

Polka, L., Jusczyk, P. W., \& Rvachew, S. (1995). Methods for studying speech perception in infants and children. In W. Strange (Ed.), Speech perception and linguistic experience: Issues in cross-language research (pp. 49-89). Timonium, MD: York Press.

Reed, M. A. (1989). Speech perception and the discrimination of brief auditory cues in dyslexic children. Journal of Experimental Child Psychology, 48, 270-292.

Rescorla, L., Roberts, J., \& Dahlsgaard, K. (1997). Late talker at 2: Outcome at age 3. Journal of Speech, Language, and Hearing Research, 40, 556-566. 
Rescorla, L., \& Schwartz, E. (1990). Outcomes of specific expressive language delay (SELD). Applied Psycholinguistics, 11, 393-408.

Rivera-Gaxiola, M., Silva-Pereyra, J., \& Kuhl, P. K. (in press). Brain potentials to native- and non-native speech contrasts in seven- and eleven-month-old American infants. Developmental Science.

Saffran, J. R. (2001). The use of predictive dependencies in language learning. Journal of Memory and Language, 44, $493-515$

Saffran, J. R., Aslin, R. N., \& Newport, E.L (1996). Statistical learning by 8-month-old infants. Science, 274, 1926-1928.

Stager, C. L., \& Werker, J. F. (1997). Infants listen for more phonetic detail in speech perception than in wordlearning tasks. Nature, 388, 381-382.

Stark, R. E., \& Heinz, J. M. (1996a). Perception of stop consonants in children with expressive and receptiveexpressive language impairments. Journal of Speech and Hearing Research, 39, 676-686.

Stark, R., \& Heinz, J. (1996b). Vowel perception in language-impaired children and language normal children. Journal of Speech and Hearing Research, 39, 860-869.

Streeter, L. A. (1976). Language perception of 2-month-old infants shows effects of both innate mechanisms and experience. Nature, 259, 39-41.

Sussman, J. E. (1993). Perception of formant transition cues to place of articulation in children with language impairments. Journal of Speech and Hearing Research, 36, $1286-1299$.

Sussman, J. E. (2001). Vowel perception by adults and children with normal language and specific language impairment: Based on steady states or transitions? Journal of the Acoustical Society of America, 109, 1173-1180.

Tallal, P. (1980). Auditory temporal perception, phonics, and reading disabilities in children. Brain and Language, 9, 182-198.

Tallal, P., Miller, S. L., Bedi, G., Byma, G., Wang, X., \& Nagarajan, S. S., et al. (1996). Language comprehension in language-learning impaired children improved with acoustically modified speech. Science, 271, 81-84.

Tallal, P., \& Piercy, M. (1974). Developmental aphasia: Rate of auditory processing and selective impairment of consonant perception. Neuropsychologia, 12, 83-93.

Tallal, P., \& Piercy, M. (1975). Developmental aphasia: The perception of brief vowels and extended stop consonants. Neuropsychologia, 13, 69-74.
Tallal, P., \& Strak, R. E. (1981). Speech acoustic cue discrimination abilities of normally developing and language impaired children. Journal of the Acoustical Society of America, 69, 568-574.

Tallal, P., Strak, R. E., \& Mellits, D. (1985). Identification of language-impaired children on the basis of rapid perception and production skills. Brain and Language, 25, 314-322.

Thal, D. J., Bates, E., Goodman, J., \& Jahn-Samilo, J. (1997). Continuity of language abilities: An exploratory study of late- and early-talking toddlers. Developmental Neuropsychology, 13, 239-273.

Trehub, S. E. (1973). Infants' sensitivity to vowel and tonal contrasts. Developmental Psychology, 9, 91-96.

Tsao, F. M. (2001). The effects of language experience on the perception of affricate and fricative consonants in Englishspeaking and Mandarin-speaking adults and young infants. Unpublished doctoral dissertation, University of Washington.

Werker, J. F., Fennell, C. T., Corcoran, K. M., \& Stager, C. L. (2002). Infants' ability to learn phonetically similar words: Effects of age and vocabulary size. Infancy, 3, $1-30$.

Werker, J. F., Polka, L., \& Pegg, J. E. (1997). The conditioned head turn procedure as a method for testing infant speech perception. Early Development and Parenting, 6, $171-178$

Werker, J. F., \& Tees, R. C. (1984). Cross-language speech perception: Evidence for perceptual reorganization during the first year of life. Infant Behavior and Development, 7, 49-63.

Werker, J. F., \& Tees, R. C. (1987). Speech perception in severely disabled and average reading children. Canadian Journal of Psychology, 41, 48-61.

Werker, J. F., \& Tees, R. C. (1999). Influences on infant speech processing: Toward a new synthesis. Annual Review of Psychology, 50, 509-535.

Wright, B. A., Lombardino, L. J., King, W. M., Puranik, C. S., Leonard, C. M., \& Merzenich, M. M. (1997). Deficits in auditory temporal and spectral resolution in languge-impaired children. Nature, 387, 176-178.

Zhang, Y. (2002). The effects of linguistic experience as revealed by behavioral and neuromagnetic measures: A cross-language study of phonetic perception by normal adult Japanese and American listeners. Unpublished doctoral dissertation, University of Washington. 